\title{
Policy-driven approach to demand management from space cooling and water heating appliances: insights from a primary survey of urban Bengaluru, India
}

\author{
Sashi Kiran Challa ${ }^{1,2, *}$, Shoibal Chakravarty ${ }^{3}$ and Kshitija Joshi ${ }^{4}$ \\ ${ }^{1}$ National Institute of Advanced Studies, Indian Institute of Science Campus, Bengaluru 560 012, India \\ ${ }^{2}$ Manipal Academy of Higher Education, Manipal 576 104, India \\ ${ }^{3}$ Divecha Centre for Climate Change, Indian Institute for Science, Bengaluru 560 012, India \\ ${ }^{4}$ Group Data and Analytics Cell, Aditya Birla Group, Bengaluru 560 064, India
}

\begin{abstract}
Appliances that provide thermal comfort services like space cooling and water heating have high energy demands and significant seasonal variation in usage. Ownership and usage of these appliances increase rapidly with income. Given the significant impact of these appliances on electricity demand, it is key to analyse their ownership and usage. A well-designed policy and standards framework can help transition households as well as manufacturers towards a higher efficiency ecosystem, and significantly lower electricity demand growth rates. In this study, we analyse ownership and usage patterns of these appliances using data from a primary survey of Bengaluru, India. We suggest some passive demand-side management frameworks based on current policies implemented for these appliance categories.
\end{abstract}

Keywords: Ownership and usage patterns, primary survey, residential electricity demand, space cooling, water heating.

HousEHOLDS use a mix of electricity and other energy sources for various end-use energy services such as heating, lighting, cooking, etc. by running appropriate appliances. These energy sources vary based on affordability, availability, reliability and access. Household income is the most important explanatory variable to understand ownership and usage of these end-use appliances, but household size, appliance stock, house type and ownership status are other important variables ${ }^{1,2}$. Among the mix of white (heavy electrical appliances) and brown (relatively lighter appliances like lights, fans, etc.) appliances that the households use, fans, desert coolers, air-conditioners (ACs) and room heaters contribute to the bulk of demand for thermal comfort. Appliances like geysers, immersion rods and instant geysers form the bulk of electricity-based water-heating demand. Fire-

\footnotetext{
*For correspondence. (e-mail: sashikiran.c@gmail.com)
}

wood, gas and solar water heaters are the other sources for heating water ${ }^{3-5}$. Both thermal comfort and waterheating appliances have a strong seasonality and peak coincidence $^{6,7}$. (In this article we do not include refrigerators, as demand from them is flat and can be considered part of the base load.)

There are few energy demand and socio-economic surveys in India that can help us understand the trends associated with ownership and usage of these appliances ${ }^{8,9}$. To address some of these gaps, we conducted a representative survey of Bengaluru, Karnataka, India covering 403 households. We covered 85 variables, across 7 categories and 19 subcategories, including data on income, appliances owned, household demographics, dwelling characteristics, and time and duration of use for a wide variety of appliances across various income categories.

We analysed the survey data to model three key aspects of thermal comfort and water-heating demand: (i) drivers of ownership of these appliances; (ii) usage patterns by income deciles and (iii) hourly load curve accounting for time of day, weekend and seasonal variations. We suggest passive demand-side management methods considering the current policies for these appliances and identify possible areas of intervention. We refer to some current successful policies and programmes to identify any key learnings that can be adopted in the policies addressing space cooling and water heating.

\section{Overview of survey}

Bengaluru is located in southern India. According to the 2011 Census, the population of the city was 8.5 million with approximately 2.1 million households and 98\% electrification, and a GDP of USD 1420 (ref. 10). The population was estimated to reach 11.9 million in 2018 (Civil Registration System, 2018, Government of Karnataka).

Bengaluru has a tropical savanna climate (Koppen $A w$ ) with the average temperature during summer (March-May) 
not exceeding $34^{\circ} \mathrm{C}$ and average humidity of approximately $40 \%$. Pre-monsoon and monsoons months (June-October) show an average temperature high of $28^{\circ} \mathrm{C}$ and average humidity of $75 \%$. Winters show an average temperature low of $17^{\circ} \mathrm{C}$ with average humidity of $40 \%$.

\section{Survey execution}

In order to identify the areas and households to survey which would be representative of Bengaluru, we used Census 2011. We built an asset index for seven assets at the ward level as the dataset did not contain any income or expenditure information. Based on the asset index and data from the local municipal body, households were categorized into five income categories. We surveyed a sample population of 403 households that were representative of the distribution of the city, collecting data on ownership and usage patterns of appliances across all households. The time of use data was captured in four time slots, 6-10 am (morning peak), $10 \mathrm{am}-6 \mathrm{pm}$, 6-11 pm (evening peak) and $11 \mathrm{pm}-6$ am along with duration of use for each appliance for summer and winter seasons.

We collected data on income, dwelling and demographics, bill amounts, appliances owned, seasonal usage data, filling some gaps indicated in the literature ${ }^{11,12}$. We divided the households into five income representative quintiles using principal component analysis (PCA) as $48 \%$ of the households did not provide income data ${ }^{13,14}$. Results of the survey presented here compare patterns observed in the households of the five quintiles. Challa et $a l .{ }^{15}$ provide a detailed survey design and analysis methodology.

\section{Results from the survey}

\section{Average electricity consumption}

Figure 1 shows the average units consumed by households in the survey, disaggregated by seasons and quintiles. The similarity between winter and survey months is because the survey was done during winter months. Figure 1 also shows that across quintiles, in summer, electricity consumption is higher, and shows an increasing trend. One reason for this is that in summers there is significant use of space cooling appliances. While these are not the only appliances that cause these significant changes in consumption, they are the major contributors.

\section{Load curve model}

We modelled hourly resolution residential load curves for each quintile using the appliance ownership and usage data collected in the survey.
The energy consumed by a household is estimated as follows

$$
E=\sum_{j, t, s, k}\left\{\sum\left(A_{i, k} \mid T_{t, s}=1\right) * P\left(H_{\mathrm{T}, \mathrm{Ai}}\right) * W_{\text {avg.Ai }}\right\},
$$

where $i$ are the appliances in the survey, $j$ the $1: n$ households, $k$ the quintiles $(1: 5), T$ the time slots, $s$ the season, $\sum\left(A_{i, k} \mid T_{t, s}=1\right)$ the total appliances of type $i$ being used in time slot $t, P\left(H_{\mathrm{T}, \mathrm{Ai}}\right)$ the probability of appliance $i$ being used in the hour $H$ of time slot $T$ and $W_{\text {avg Ai }}$ is the average wattage of appliance $i$.

\section{Analysis of thermal comfort appliances}

Fans, desert coolers, ACs and electric room heaters were the thermal comfort appliances covered in the survey. Figure 2 shows that all households own fans, as these are one of the first appliances purchased by most households ${ }^{16,17}$. The ownership of other more expensive space comfort appliances increases across quintiles. Bengaluru's mild winters do not warrant significant use of space heaters; therefore the low ownership numbers.

Table 1 presents the Pearson correlation coefficients for ownership of coolers and ACs with respect different indicators. Values highlighted in blue and orange indicate positive and negative correlations respectively, at a significance of 0.05 . Both coolers and ACs have a strong correlation to income. AC ownership also indicates significant correlation to own households and a negative correlation to rental households. This is understandable, as people who own households would invest in the high upfront cost to buy an AC.

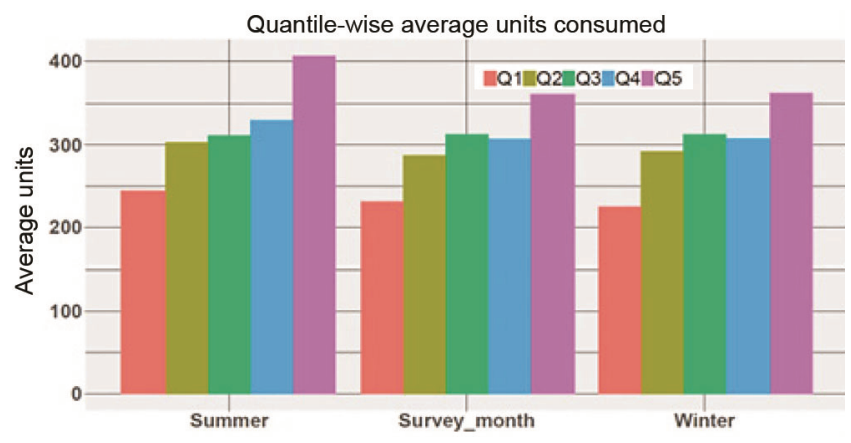

Figure 1. Average units consumed by households.

Table 1. Correlations of ownership of cooing appliances

\begin{tabular}{lrr}
\hline & Cooler & \multicolumn{1}{c}{ AC } \\
\hline Income & 0.195 & 0.382 \\
Independent household $(\mathrm{HH})$ & 0.009 & 0.084 \\
Apartment & -0.009 & -0.084 \\
Own HH & 0.132 & 0.227 \\
Rental HH & -0.151 & -0.207 \\
\hline
\end{tabular}




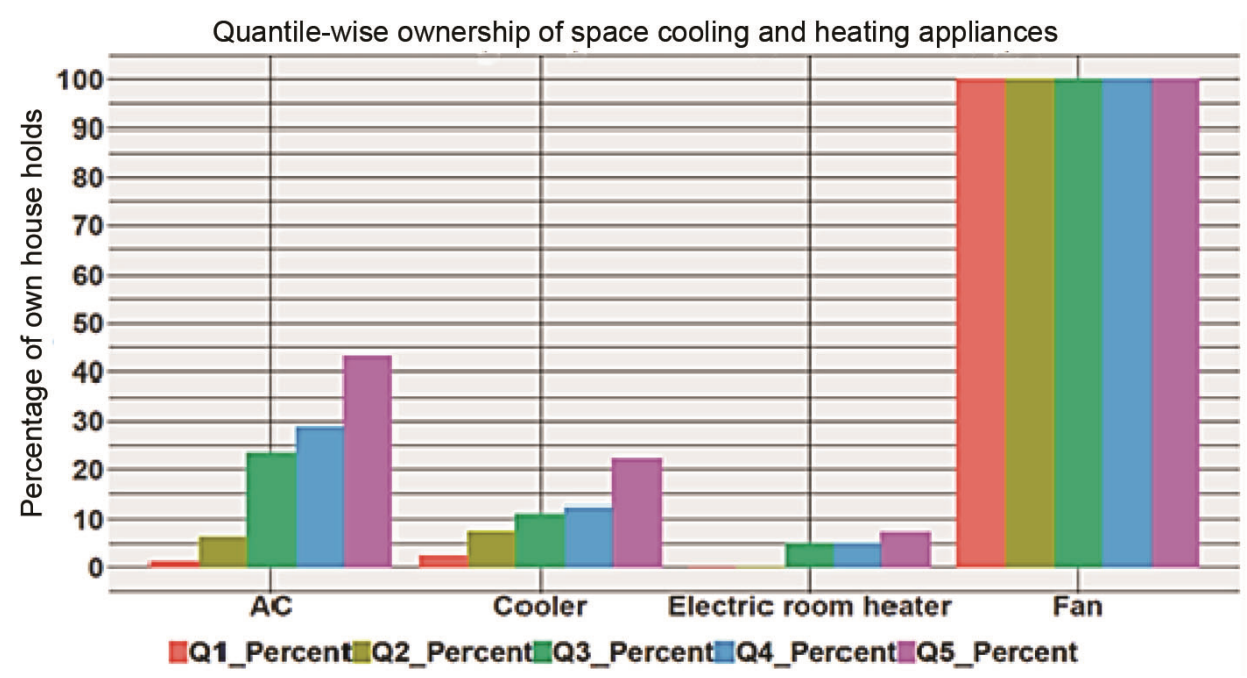

Figure 2. Ownership of space cooling appliances.

Table 2. Seasonal usage patterns of space comfort appliances (\%)

\begin{tabular}{|c|c|c|c|c|c|c|c|c|c|}
\hline \multirow[b]{2}{*}{ Quintile } & \multirow[b]{2}{*}{ Appliance } & \multicolumn{4}{|c|}{ Summer } & \multicolumn{4}{|c|}{ Winter } \\
\hline & & $6-10 \mathrm{am}$ & $10 \mathrm{am}-6 \mathrm{pm}$ & $6-11 \mathrm{pm}$ & $11 \mathrm{pm}-6 \mathrm{am}$ & $6-10 \mathrm{am}$ & $10 \mathrm{am}-6 \mathrm{pm}$ & $6-11 \mathrm{pm}$ & $11 \mathrm{pm}-6 \mathrm{am}$ \\
\hline \multirow[t]{4}{*}{ Q1 } & Fan & 0.22 & 0.63 & 0.74 & 1.00 & 0.04 & 0.16 & 0.15 & 0.80 \\
\hline & Cooler & 0.00 & 0.00 & 0.00 & 0.03 & 0.00 & 0.00 & 0.00 & 0.00 \\
\hline & $\mathrm{AC}$ & 0.00 & 0.00 & 0.00 & 0.01 & 0.00 & 0.00 & 0.00 & 0.00 \\
\hline & Heater & 0.00 & 0.00 & 0.00 & 0.00 & 0.00 & 0.00 & 0.00 & 0.00 \\
\hline \multirow[t]{4}{*}{ Q2 } & Fan & 0.23 & 0.84 & 0.81 & 0.99 & 0.05 & 0.13 & 0.11 & 0.73 \\
\hline & Cooler & 0.01 & 0.01 & 0.00 & 0.04 & 0.00 & 0.00 & 0.00 & 0.00 \\
\hline & $\mathrm{AC}$ & 0.00 & 0.01 & 0.00 & 0.06 & 0.00 & 0.01 & 0.00 & 0.00 \\
\hline & Heater & 0.00 & 0.00 & 0.00 & 0.00 & 0.00 & 0.00 & 0.00 & 0.00 \\
\hline \multirow[t]{4}{*}{ Q3 } & Fan & 0.32 & 0.83 & 0.90 & 0.99 & 0.05 & 0.14 & 0.15 & 0.74 \\
\hline & Cooler & 0.00 & 0.04 & 0.03 & 0.09 & 0.00 & 0.00 & 0.00 & 0.00 \\
\hline & $\mathrm{AC}$ & 0.00 & 0.06 & 0.01 & 0.22 & 0.00 & 0.00 & 0.00 & 0.01 \\
\hline & Heater & 0.00 & 0.00 & 0.00 & 0.00 & 0.01 & 0.00 & 0.00 & 0.05 \\
\hline \multirow[t]{4}{*}{ Q4 } & Fan & 0.29 & 0.93 & 0.90 & 0.98 & 0.03 & 0.19 & 0.16 & 0.68 \\
\hline & Cooler & 0.00 & 0.04 & 0.03 & 0.10 & 0.00 & 0.00 & 0.00 & 0.01 \\
\hline & $\mathrm{AC}$ & 0.00 & 0.06 & 0.03 & 0.28 & 0.01 & 0.00 & 0.00 & 0.01 \\
\hline & Heater & 0.00 & 0.00 & 0.00 & 0.00 & 0.01 & 0.00 & 0.01 & 0.05 \\
\hline \multirow[t]{4}{*}{ Q5 } & Fan & 0.30 & 0.85 & 0.94 & 1.00 & 0.01 & 0.27 & 0.26 & 0.82 \\
\hline & Cooler & 0.01 & 0.06 & 0.03 & 0.17 & 0.00 & 0.00 & 0.00 & 0.00 \\
\hline & $\mathrm{AC}$ & 0.00 & 0.06 & 0.05 & 0.40 & 0.00 & 0.00 & 0.00 & 0.04 \\
\hline & Heater & 0.00 & 0.00 & 0.00 & 0.00 & 0.00 & 0.00 & 0.00 & 0.07 \\
\hline
\end{tabular}

The usage patterns of each cooling appliance, seasonally presented in Table 2, show that fans in summer are used by all households at night with close to $80 \%$ households using them during the day, while in winters we see between $75 \%$ and $80 \%$ usage at night with approximately $25 \%-30 \%$ usage during the day, making space cooling driven by fans a consistent 'hidden' demand ${ }^{18}$. Among cooling appliances, coolers are the least owned (Figure 2), with ownership and usage skewed towards the top three quintiles, unlike fans. Top quintile households likely prefer ACs instead due to their superior performance at less than double the price. In the case of AC, ownership and usage are concentrated in the top three quintiles and exceed cooler ownership. AC usage peaks at night in summers and is significantly high in the top quintile. Finally, space heater ownership and usage are not significant given Bengaluru's mild winters, and are mostly limited to the elderly.

\section{Load from thermal comfort appliances}

Figure 3 shows the average load from various thermal comfort appliances seasonally, for a typical household in each quintile. The load curves do not include space heaters, given very low ownership. Electric fan loads are 

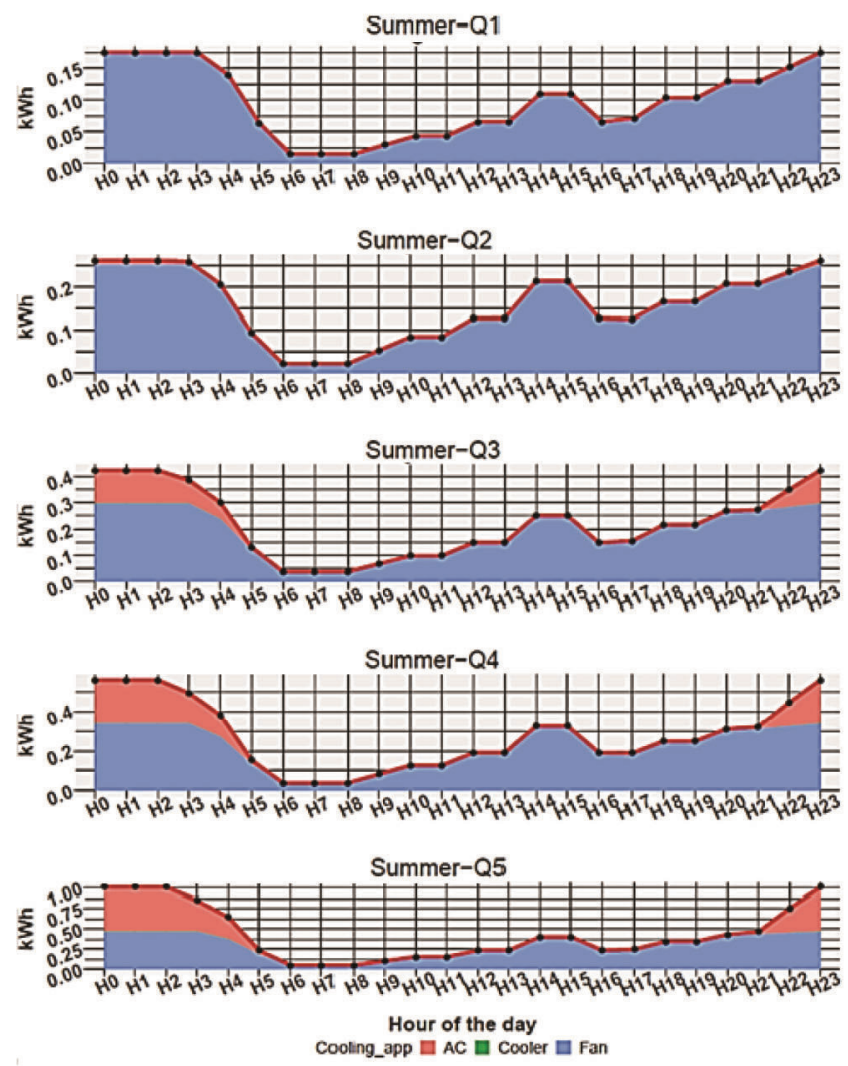
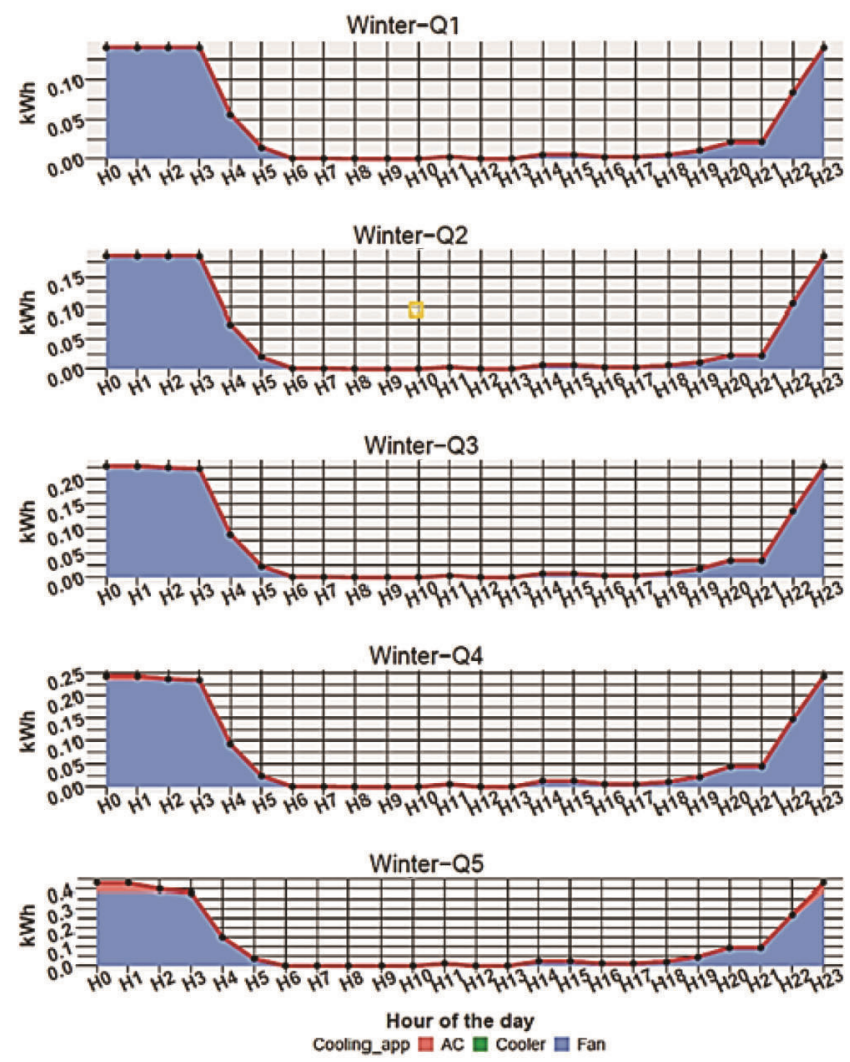

Figure 3. Contributions to the load curves from space cooling appliances for summer and winter.

significant all year round ${ }^{18}$. In summer, seasonal AC usage in the higher quintiles, mostly at night, makes up almost half of the total cooling load. However, coolers are not a significant load compared to the other two appliances.

\section{Water heating}

Households use three major ways to heat water; electricity, solar energy and non-electric (firewood or LPG gas) (Figure 4).

Under the electricity-based water heating appliances, we have immersion rods, instant geysers and geysers. Immersion rods are the cheapest and least energyefficient, priced about a tenth of a regular geyser (approximately Rs 400-500). Instant geysers heat water instantaneously as it passes through them and typically have a higher energy footprint compared to traditional storagebased geysers. They are more efficient than immersion rods but not as efficient as storage-based geysers and typically cost half as much as a regular geyser (approximately Rs 3000-4000). Storage-based geysers are comparatively the most efficient, using a thermostat-based on-off cycle and are the most expensive (approximately Rs 8000-12,000). From Figure 4, it can be seen that ownership of these three types of water heaters has a correla- tion with income quintiles, with ownership increasing steadily with quintiles.

Under solar-based water heaters, there is one model with a version that comes with an in-built electric heating element. These are more expensive than geysers, and Figure 4 shows that there is a strong correlation between income and ownership. Installation of these solar water heaters for residences was mandated by the Government of Karnataka in 2007.

The non-electric modes of water heating - firewood, LPG geysers and cooking stoves are limited to the lower income quintiles.

Table 3 presents the Pearson correlation coefficients for ownership of water heating appliances for various household indicators with blue and orange cells indicating positive and negative correlations respectively, with a significance of 0.05 . Geysers and solar water heaters have a significant positive correlation with income, with immersion rods showing a negative correlation. Solar water heater ownership is significantly correlated with home ownership likely due to the higher upfront costs of the system.

Table 4 presents the time and seasonality of use of the electricity-based water heaters (given the scope of the paper is limited to electricity-based water heating methods). The usage of immersion rods is limited to lower 


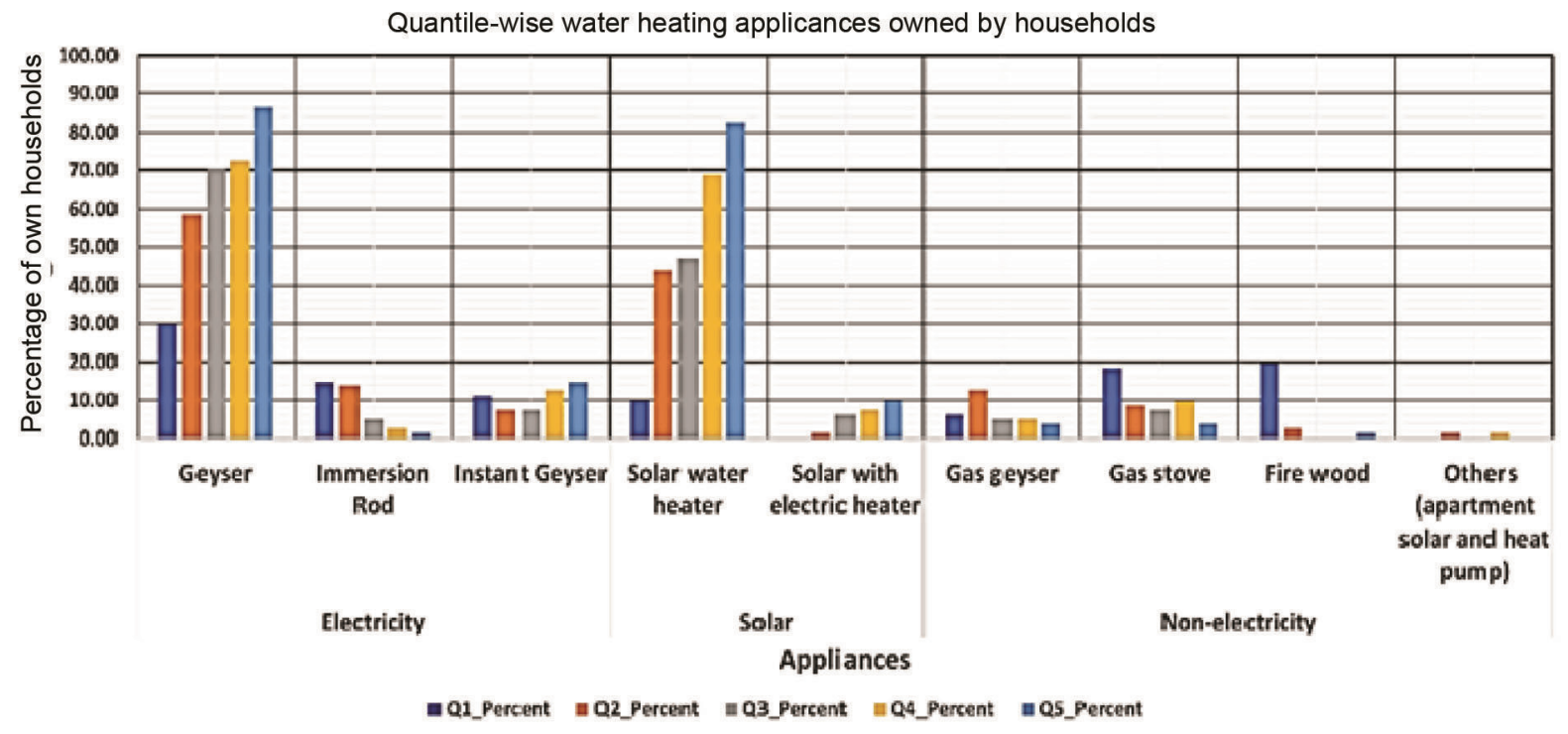

Figure 4. Percentage ownerships of different water heating appliances.
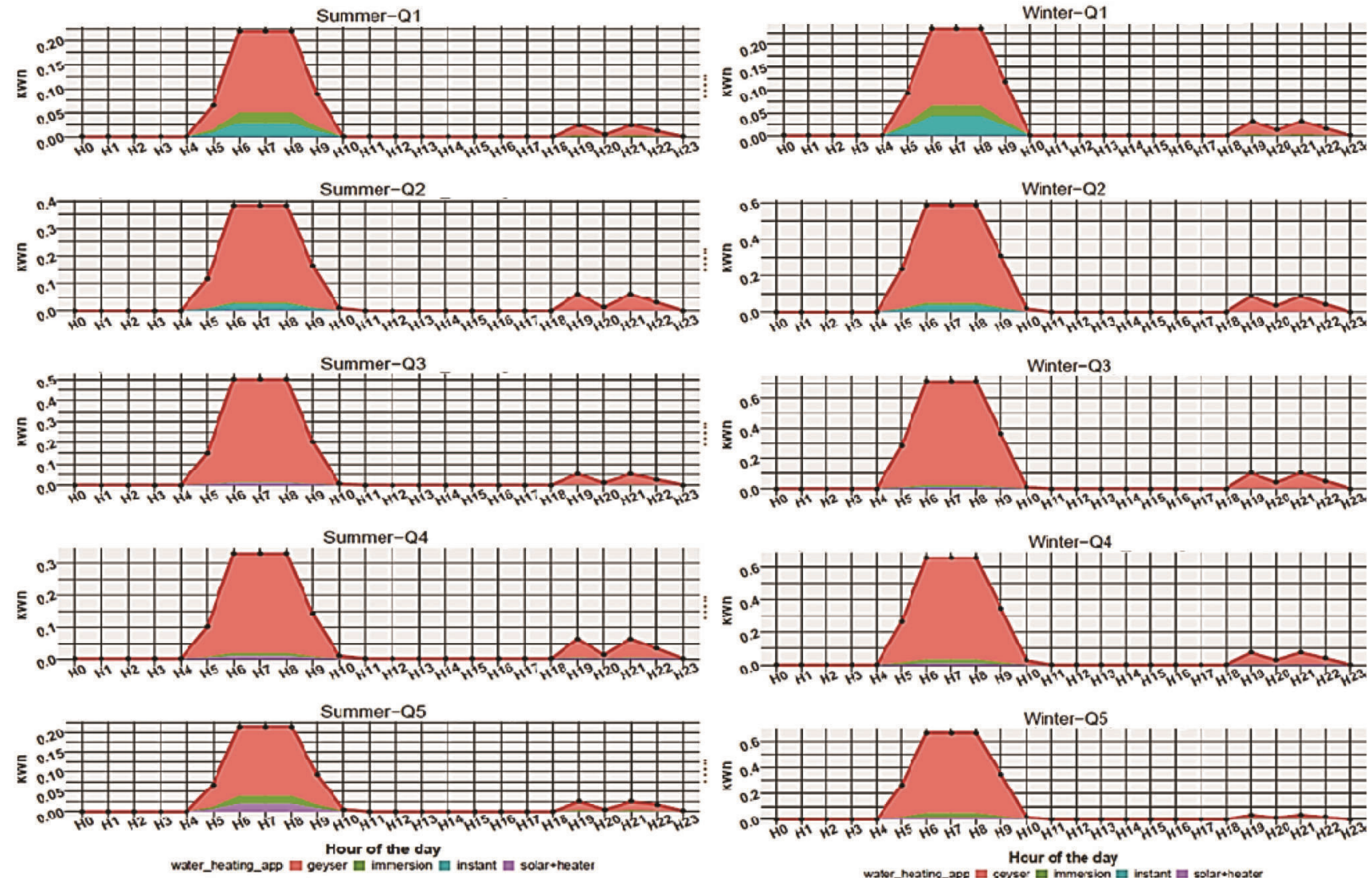

Figure 5. Contributions to the load curve from water heating appliances across income-representative quintiles.

income quintiles with significant use during winter mornings. In the case of instant geysers, we observed approximately the same percentage of ownership across quintiles, with uniform seasonal use in the lower quin- tiles, doubling as we move up the quintiles. Geysers are the most popular water-heating appliances with strong seasonal trend and significant use by upper quintile households in winter (Table 4). 


\section{Load curve contributions by water heating appliances}

Figure 5 presents the average demand from various water heating appliances seasonally, for a typical household in each quintile. The seasonal correlation observed in Table 4 is reflected in Figure 5. The figure also shows that there is significant increase in usage from the upper quintiles, with demand increasing approximately by a factor of two between summer and winter. The use of instant geysers and geysers increases significantly in winter. This is because the top two quintiles own a higher percentage of both solar water heaters and geysers, with reduction in demand during summer attributed to the use of these solar water heaters.

In the lowest income quintile, there was no significant seasonal change in demand as a significant percentage of households used non-electric modes of water heating along with a low penetration of solar water heaters. The lowest income quintile was either dependent on inefficient electric appliances, or used firewood and gas stoves.

\section{Passive demand-side management-based policy interventions}

Figures 3 and 5 present significant demands that arise from space comfort and water heating appliances respectively. It is imperative to manage such demands for efficient peak management and dispatch planning ${ }^{8}$. The figures also show probable changes in demand as households transition to more energy-intensive lifestyles ${ }^{5,16,19}$. In order to manage this peak demand, we introduce the idea of passive demand response and a policy intervention framework built on it.

Passive demand-side management (DSM) uses measures that reduce the peak demand by introducing either energy-efficient appliances or by shifting the peak demand to off-peak hours with voluntary (not incentivized or disincentivized) end-user participation. Given the lack of demand response programmes targeted at residences in the country and the comparatively inflexible nature of demand from the two appliance categories (space comfort and water heating), we propose policy interventions designed to bring down the intensity of peak demand from these appliances. We draw on similar, successful programmes to help build this framework. The

Table 3. Correlations of ownership of water heating appliances

\begin{tabular}{lccc}
\hline & Geyser & Immersion & Solar \\
\hline Income & 0.399 & -0.179 & 0.487 \\
Independent HH & -0.109 & -0.003 & 0.229 \\
Apartment & 0.109 & 0.003 & 0.109 \\
Own HH & 0.005 & -0.062 & 0.317 \\
Rental HH & -0.020 & 0.077 & -0.306 \\
\hline
\end{tabular}

star rating programme of the Bureau of Energy Efficiency has a role to play in this framework. This programme rates appliances from one to five stars based on increasing efficiency, and also progressively upgrades the efficiency standards periodically to make the entire fleet of appliances more efficient over time ${ }^{19}$.

\section{Space cooling}

\section{Fans}

Table 2 indicates that fans are among the appliances that are used significantly year-round ${ }^{18}$, making them a good target for efficiency improvement programmes, also considering their significantly long life cycle and low replacement frequency.

In India, five-star rated fans (high efficiency) are available, which are not significantly more expensive compared to low-efficiency fans. On average, a lowefficiency fan consumes approximately $75 \mathrm{~W}$, while fivestar fans consumes $50 \mathrm{~W}$ (authors' estimates from market data). On average, a household uses fans for approximately $12 \mathrm{~h}$ a day, year-round. Based on these estimates, an average saving of approximately 110 units/year/fan can be achieved, translating into significant savings for the households and significant load reduction for the grid. Currently, private distribution utilities like Tata Power and Reliance Energy in Mumbai provide schemes to exchange old fans for efficient ones ${ }^{20}$.

Considering the ubiquitous ownership of fans and the potential of savings from passive demand response, a good template to follow is Domestic Efficiency Lighting Programme (DELP) (UJALA scheme), a joint venture between state utilities and the government. It offered LED bulbs at $20-40 \%$ of the market price, providing a monthly payment plan for low-income households ${ }^{21,22}$. The programme has seen significant success with estimated annual savings of 47 million $^{23}$. The success of the programme was also visible in our survey, with an average $73 \%$ of the households using LED bulbs.

The draft India Cooling Action Plan (ICAP) has a section dedicated to tackling residential demand from cooling. For fans though, the draft only proposes standardizing efficiency labelling and improving minimum efficiency standards. Efficiency labelling by itself does not always lead to households buying the most efficient appliance. Our survey provides little evidence for any correlation between ratings and income (Table 5). The other key point that the policy fails to address is the replacement of old stock, given the long lifetimes of fans. Just availability of more efficient models will not ensure replacement. Given the success of $\mathrm{DELP}^{23}$, establishing a similar programme, enabling ease of exchange and installation of efficient fans and offering staggered payment options to low income households could maximize penetration and demand management. 
Table 4. Seasonal usage patterns of water heating appliances (\%)

\begin{tabular}{|c|c|c|c|c|c|c|c|c|c|}
\hline \multirow[b]{2}{*}{ Quintile } & \multirow[b]{2}{*}{ Appliance } & \multicolumn{4}{|c|}{ Summer } & \multicolumn{4}{|c|}{ Winter } \\
\hline & & $6-10 \mathrm{am}$ & $10 \mathrm{am}-6 \mathrm{pm}$ & $6-11 \mathrm{pm}$ & $11 \mathrm{pm}-6 \mathrm{am}$ & $6-10 \mathrm{am}$ & $10 \mathrm{am}-6 \mathrm{pm}$ & $6-11 \mathrm{pm}$ & $11 \mathrm{pm}-6 \mathrm{am}$ \\
\hline \multirow[t]{3}{*}{ Q1 } & Geyser & 0.28 & 0.00 & 0.04 & 0.00 & 0.28 & 0.00 & 0.05 & 0.00 \\
\hline & Immersion rod & 0.10 & 0.00 & 0.00 & 0.00 & 0.15 & 0.00 & 0.00 & 0.00 \\
\hline & Instant geyser & 0.10 & 0.00 & 0.01 & 0.00 & 0.10 & 0.00 & 0.01 & 0.00 \\
\hline \multirow[t]{3}{*}{ Q2 } & Geyser & 0.36 & 0.03 & 0.06 & 0.00 & 0.55 & 0.03 & 0.09 & 0.00 \\
\hline & Immersion rod & 0.09 & 0.00 & 0.00 & 0.00 & 0.14 & 0.00 & 0.00 & 0.00 \\
\hline & Instant geyser & 0.04 & 0.00 & 0.00 & 0.00 & 0.08 & 0.00 & 0.00 & 0.00 \\
\hline \multirow[t]{3}{*}{ Q3 } & Geyser & 0.48 & 0.01 & 0.05 & 0.00 & 0.68 & 0.01 & 0.10 & 0.00 \\
\hline & Immersion rod & 0.01 & 0.00 & 0.00 & 0.00 & 0.05 & 0.00 & 0.00 & 0.00 \\
\hline & Instant geyser & 0.02 & 0.00 & 0.01 & 0.00 & 0.06 & 0.00 & 0.01 & 0.00 \\
\hline \multirow[t]{3}{*}{ Q4 } & Geyser & 0.34 & 0.03 & 0.06 & 0.00 & 0.68 & 0.04 & 0.08 & 0.00 \\
\hline & Immersion rod & 0.00 & 0.00 & 0.00 & 0.00 & 0.03 & 0.00 & 0.00 & 0.00 \\
\hline & Instant geyser & 0.04 & 0.00 & 0.01 & 0.00 & 0.09 & 0.00 & 0.01 & 0.01 \\
\hline \multirow[t]{3}{*}{ Q5 } & Geyser & 0.21 & 0.01 & 0.02 & 0.01 & 0.73 & 0.02 & 0.04 & 0.00 \\
\hline & Immersion rod & 0.00 & 0.00 & 0.00 & 0.00 & 0.01 & 0.00 & 0.00 & 0.00 \\
\hline & Instant geyser & 0.06 & 0.01 & 0.01 & 0.00 & 0.10 & 0.01 & 0.01 & 0.00 \\
\hline
\end{tabular}

Table 5. Distribution of star rating and tonnage of air-conditioners (\%)

\begin{tabular}{lccccc}
\hline Star rating & Q1 & Q2 & Q3 & Q4 & Q5 \\
2 & 0 & 0 & 5.26 & 8.70 & 0 \\
3 & 100 & 80 & 63.16 & 21.74 & 45.71 \\
5 & 0 & 0 & 10.53 & 30.43 & 20 \\
NA & 0 & 20 & 15.79 & 21.74 & 22.86 \\
Tonnage & Q1 & Q2 & Q3 & Q4 & Q5 \\
1 & 0 & 20 & 21.05 & 39.13 & 40 \\
1.2 & 0 & 0 & 0 & 4.35 & 0 \\
1.5 & 100 & 80 & 63.16 & 43.48 & 51.43 \\
2 & 0 & 0 & 15.79 & 13.04 & 8.57 \\
NA & 0 & 0 & 0 & 0 & 0 \\
\hline
\end{tabular}

\section{Air conditioners}

From Table 2 we see that residential ACs are primarily used during night time in summers. This adds significantly to the load curve (Figure 3). Table 5 presents the distribution of tonnage and star rating of these ACs. We see from the table that most of the ACs owned are two and three stars, with very few five-star ACs. In terms of capacity, most of the ACs are either 1 tonne or 1.5 tonnes in capacity.

Some studies highlight the impacts on the grid when energy-efficient ACs are used $\mathrm{d}^{24,25}$ and while others show that as income increases, people tend to run ACs at lower temperatures $^{26}$. Therefore, here efficient ACs would make a significant difference. In most cases, as seen from Table 5 , the households might not size the ACs effectively (Table 6), either over- or under-sizing it. Figure 3 shows the significance of demand for ACs. An intervention to address these issues is therefore important.

ICAP proposes to establish a range of base temperature set points, ranging from $24^{\circ} \mathrm{C}$ to $26^{\circ} \mathrm{C}$, for ACs based on thermal comfort standards ${ }^{27,28}$. The idea is to enable behaviour change in the end-user to use ACs at the minimum set points. It is projected that this could save close to 20 billion units annually ${ }^{27}$. While it sounds good, there are few key shortcomings. First, the estimation of 20 billion units is based on new, and more efficient models, ignoring demand from the current stock. The other issue is that efficiency ratings have Indian Seasonal Energy Efficiency Ratio (ISEER) values ranging from 3.10 for one star to 4.50 for five stars. This leads to a significant variance in the number of units consumed by ACs across star ratings. The next related issue is of price. A five-star AC on average is between $25 \%$ and $40 \%$ more expensive than a three-star AC. Therefore, in order to achieve savings from $\mathrm{ACs}$, incentive programmes to encourage consumers to purchase more efficient models and awareness programmes at points of sale on sizing need to be put in place $^{24,25}$.

In the case of older stock, there is no easy way to implement an exchange/replacement programme. However, considering ACs are lifestyle appliances owned by the upper income quintiles, an exchange programme with discounted prices for replacement models can be an exploratory approach. This is important considering that there is no way to implement the proposed temperature caps for the current stock in use.

\section{Water heating appliances}

The Government of Karnataka implemented under the Energy Conservation Act of 2001, a policy, mandating residences with a minimum floor area of $600 \mathrm{sq} . \mathrm{ft}$ to install solar water heating ( $\mathrm{SWH})$ systems $^{29}$.

Table 6 shows that $65 \%$ of households in quintile 1 and all households from quintile 2 onwards have a minimum built-up area of at least $600 \mathrm{sq}$. ft. This would mean that all households from Q2 to Q5 must have SWH installed. We see that none of the quintiles have $100 \%$ installation (Figure 4), with $80 \%$ penetration ranging from $10 \%$ to $80 \%$ between quintiles 1 and 5 . One reason for the low 
Table 6. Built-up area of households across income quintiles

\begin{tabular}{lccccc}
\hline & \multicolumn{5}{c}{ Household characteristics } \\
\cline { 2 - 5 } Variable & Q1 & Q2 & Q3 & Q4 & Q5 \\
\hline Average built-up area (sq. ft) & 667.41 & 938.75 & 1154.48 & 1262.24 & 1740.44 \\
Minimum built-up area (sq. ft) & 200 & 600 & 600 & 620 & 800 \\
Maximum built-up area (sq. ft) & 1100 & 1600 & 2400 & 2500 & 4000 \\
\hline
\end{tabular}

Table 7. Usage of geysers versus solar water heaters (\%)

\begin{tabular}{lccccc}
\hline Quintile & Q1 & Q2 & Q3 & Q4 & Q5 \\
\hline Solar water heaters & & & & & \\
$\quad$ Summer & 8 & 38 & 33 & 51 & 20 \\
Winter & 6 & 15 & 16 & 17 & 18 \\
Geyser & & & & & \\
$\quad$ Summer & 28 & 36 & 48 & 33 & 66 \\
Winter & 28 & 55 & 67 & 67 & 72 \\
\hline
\end{tabular}

ownership of SWH in the first quintile was the price. The average starting price of the system is approximately Rs 35,000 (USD 500). In the other quintiles, one of the key reasons was construction of the households before the policy.

Next, if we consider usage patterns of SWH, Table 7 shows that all the households which own SWH do use not them irrespective of season, and prefer using geysers. During winters, when the need for hot water is more, people tend to use geysers more than SWH as observed across quintiles. One of the reasons for this was the inefficiency of the system in providing water of desired temperature, consistently. Also, it was noted that the systems were rarely serviced. The primary reason for this was lack of information on the need/availability of servicing options.

Based on these observations from the survey, some key points of failure are: (i) lack of affordability of the system by a large proportion of the lower income households, (ii) the inefficacy of the policy to stringently implement installation of the systems in households constructed before policy implementation, and (iii) lack of information/awareness/avenues for periodic checkup.

Some steps that can be taken to better manage water heating demand passively are given below. (1) Mandating system providers to have a service programme to enable a behavioural change in the users, ensuring service regularity with a list of service providers on Government portals and in offices.

(2) Stricter enforcement of retrofitting SWH to households that were built before the policy by enabling periodic checks of households.

(3) Critically, for lower income households, provision of soft loans and monthly payment options to increase affordability and access to the system. We have the template of Surya Raitha (solar irrigation pump programme), which has proved to be viable and successful. It is critical for lower-income households to procure these systems, as close to $20 \%$ of the households use either firewood or less efficient electricity-based methods. Aiding these households in transition by providing ease of access can have a significant impact on demand reduction.

\section{Summary}

We present findings from the urban electricity use survey conducted in Bengaluru, to identify ownership and usage patterns of household appliances. We also present results for ownership and usage of space comfort and water heating appliances forming the bulk of the demand from these households. The results outline the use of each appliance seasonally and their contributions to the load curve. We outline passive demand management methodologies based on current policies while looking towards current successful programmes to propose a framework to replace fans, suggesting an increase in purchase of new and replacement of old fans, offering approximate savings of 110 units/year/fan/household. We indicate some shortcomings of the ICAP policy, suggesting possible modifications to better address the demand from ACs.

We highlighted key points from the current SWH heater policy for Karnataka and indicated where it falls short, listing issues that end-users typically face and a potential approach to increasing installations. Finally, we suggest steps to transition low-income households from using fire wood and less efficient electricity-based methods, to more efficient methods of water heating.

While we acknowledge that these suggestions might not aid in $100 \%$ transition to more efficient appliance usages, they will help identify the correct right pathways to begin this transition based on appropriate survey data, especially for a major metro like Bengaluru with almost universal electrification of households. Bengaluru's population is projected to increase to 13.2 million in 2021 (ref. $30)$. With growth of this scale, it is critical to implement measures to reduce electricity demand. To expedite and efficiently manage the peak demand using passive demand-side programmes at scale will require active involvement of the state utilities and the government.

1. Murthy, K. V. N. and Sumithra, G. D., End-uses of electricity in households of Karnataka state, India. Energy Sustain. Dev., 2001, 5(3), 81-94; https://doi.org/10.1016/S0973-0826(08)60278-1.

2. World Bank, Residential consumption of electricity in India. The World Bank, 2008, pp. 1-73; https://doi.org/http://www.moef.nic. in/downloads/public-information/Residentialpowerconsumption. pdf 


\section{RESEARCH ARTICLES}

3. Khosla R. and Chunekar, A. (eds), Plugging. In A Collection of Insights on Electricity Use in Indian Homes. Research Report, Centre for Policy Research, New Delhi and Prayas (Energy Group), Pune, 2017.

4. Narasimha Rao, M. and Reddy, B. S., Variations in energy use by Indian households: an analysis of micro level data. Energy, 2007, 32(2), 143-153; https://doi.org/10.1016/j.energy.2006.03.012.

5. Pachauri, S., An analysis of cross-sectional variations in total household energy requirements in India using micro survey data. Energy Policy, 2004, 32(15), 1723-1735; https://doi.org/ 10.1016/S0301-4215(03)00162-9.

6. Garg, A., Shukla, P. R., Maheshwari, J. and Upadhyay, J., An assessment of household electricity load curves and corresponding $\mathrm{CO}_{2}$ marginal abatement cost curves for Gujarat state, India. Energy Policy, 2014, 66, 568-584; https://doi.org/10.1016/ j.enpol.2013.10.068.

7. Isaac, M. and Van Vuuren, D. P., Modeling global residential sector energy demand for heating and air conditioning in the context of climate change. Energy Policy, 2009, 37(2), 507-521.

8. Chunekar, A., Varshney, S. and Dixit, S., Residential electricity consumption in India: what do we know? Prayas (energy group), December 2016

9. Electricity in Megacities, Prayas Energy Group, Pune, Prayas, 2012, pp. 1-33.

10. The Brookings Institution, 'Global Metro Monitor', Brookings; https://www.brookings.edu/wp-content/uploads/2015/01/bmpp_GMM_ final.pdf

11. Dukkipati, S., Iyer, R. K. and Sreenivas, A., An assessment of energy data management in India, Prayas Energy Group, Pune, October 2016.

12. Matsumoto, S., How do household characteristics affect appliance usage? Application of conditional demand analysis to Japanese household data. Energy Policy, 2016, 94, 214-223; https://doi.org/ 10.1016/j.enpol.2016.03.048.

13. Moser, C. and Felton, A., The construction of an asset index measuring asset accumulation in Ecuador, Chronic Poverty Research Centre, Working Paper No. 87, 21 July 2007; http://dx.doi.org/ $10.2139 /$ ssrn. 1646417.

14. Filmer, D. and Pritchett, L. H., Estimating wealth effects without expenditure data - or tears: an application to educational enrollments in states of India. Demography, 2001, 38(1), 115-132.
15. Challa, S. K., Chakravarty, S. and Joshi, K., Uploaded manuscript, SSRN, http://ssrn.com/abstract $=3476549$

16. Rathi, S. S., Chunekar, A. and Kadav, K., Appliance ownership in India: evidence from NSSO household expenditure surveys 200405 and 2009-10. Prayas Energy Group, Pune, 2012.

17. van Ruijven, B. J., Energy and development: a modelling approach, Thesis, Utrecht University, The Netherlands, 2008.

18. Singh, D., Barve, A. and Sant, G., Ceiling fans: the overlooked appliance, Prayas Energy Group, Pune, 2010.

19. https://beeindia.gov.in/content/star-labelled-appliances

20. https://www.tatapower.com/media/PressReleaseDetails/30/Tata-Powerlaunches-Super-Efficient-BLDC-Ceiling-Fan-program-for-the-consumers-in-Mumbai

21. Rao, N. D. and Ummel, K., White goods for white people? Drivers of electric appliance growth in emerging economies. Energy Res. Soc. Sci., 2017, 27, 106-116.

22. https://www.iea.org/policiesandmeasures/pams/india/name-166389en.php

23. http://www.ujala.gov.in/

24. Phadke, A. A., Abhyankar, N. and Shah, N., Avoiding 100 new power plants by increasing efficiency of room air conditioners in India: opportunities and challenges. LBNL report LBNL-6674e, 2014.

25. Abhyankar, N., Shah, N., Park, W. Y. and Phadke, A. A., Accelerating energy efficiency improvements in room air conditioners in India: potential, costs-benefits, and policies. LBNL report, LBNL1005798, 2017.

26. Gupta, E., The effect of development on the climate sensitivity of electricity demand in India. Climate Change Econ., 2016, 7(02), 1650003.

27. http://www.indiaenvironmentportal.org.in/files/file/DRAFT-India\%20Cooling\%20Action\%20Plan.pdf

28. https://aeee.in/thermal-comfort-for-all-project-with-lbn1/

29. http://kredlinfo.in/EC/mandatory\%20solar\%20water\%20heater.pdf

30. DES projections of Bengaluru population; https://des.kar. nic.in/docs/Projected\%20Population\%202012-2021.pdf

Received 2 April 2020; revised accepted 16 February 2021

doi: $10.18520 / \mathrm{cs} / \mathrm{v} 120 / \mathrm{i} 11 / 1712-1720$ 